\title{
Lausanner Nebelpetarden zu Facebook
}

Anmerkungen zum Urteil des

Bundesgerichts 6B_440/2019 vom

18. November 2020

(zur Publikation vorgesehen)

Das Bundesgericht prüft die Anwendung des Medienstrafrechts auf die Social-Media-Plattform «Facebook». Die Frage, ob Facebook ein Medium sei, wird zwar traktiert, aber nicht wirklich beantwortet. Zudem bleibt völlig unklar, warum das Haftungsprivileg des Art. 28 StGB im vorliegenden Zusammenhang nicht gilt, obwohl Facebook ein Medium zu sein scheint.

I. Eine Ehrverletzung auf «Facebook»

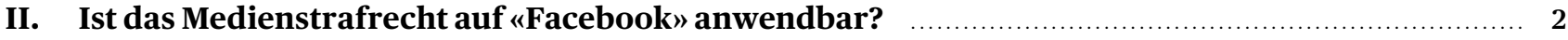

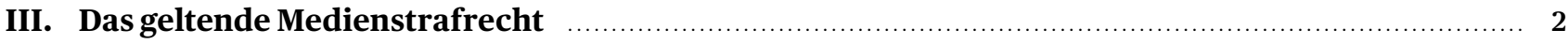

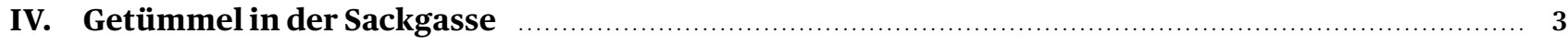

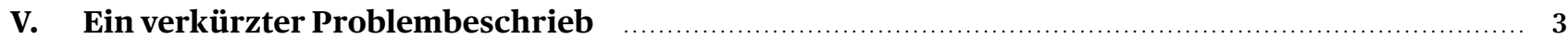

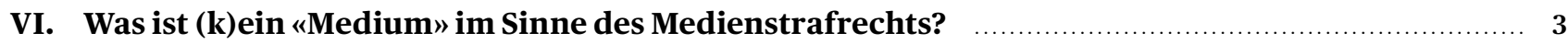

VII. Die bundesgerichtliche Exegese zum massgeblichen Medienbegriff, Teil $1 \quad \ldots \ldots \ldots \ldots \ldots \ldots \ldots \ldots \ldots \ldots$

VIII. Die bundesgerichtliche Exegese zum massgeblichen Medienbegriff, Teil $2 \quad \ldots \ldots \ldots \ldots \ldots \ldots \ldots \ldots \ldots .7$

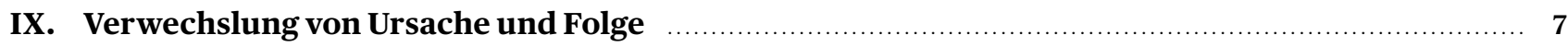

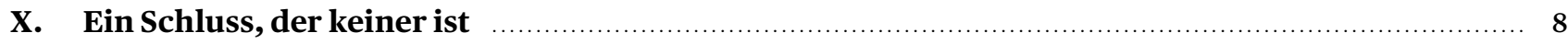

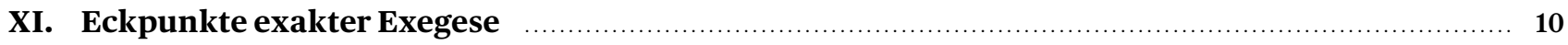

Zitiervorschlag:

MATTHIAS SCHWAIBOLD, Lausanner Nebelpetarden zu Facebook, sui generis 2021, S. 1

Dr. Matthias Schwaibold, Rechtsanwalt in Zürich, Lehrbeauftragter für Medienrecht an der Universität St. Gallen. Ich danke Sedlex Avocats Lausanne, für die freundliche Hilfe bei der Beschaffung der nachfolgend erwähnten Literatur. Weiter danke ich RA lic.iur. Simon Canonica und RA MLaw Luca Ranzoni von sui generis für weiterführende Hinweise und kritische Anmerkungen zu meinem Entwurf; sie sind in der vorliegenden Fassung unausgewiesen aufgegriffen worden.

URL: sui-generis.ch/162

DOI: https://doi.org/10.21257/sg.162

Dieses Werk ist lizenziert unter einer Creative Commons Namensnennung - Weitergabe unter gleichen Bedingungen 4.0 International Lizenz. 


\section{Eine Ehrverletzung auf «Facebook»}

1 Manchmal hat man den Eindruck, das Bundesgericht zündet zuerst eine Nebelpetarde, irrt sodann im eigenen Nebel umher, und wenn der sich verzogen hat, steht es wieder am Anfang. Vorliegend sind Ausgangs- und Endpunkt der Begriff des «Mediums» im Strafrecht.

2 Versuchen wir, den Sachverhalt aus dem wieder einmal unendlich wortreich ausgefallenen Entscheid zusammenzufassen: Der Nutzer «Indyvegan» verbreitete über die sogenannte «Social-Media-Plattform» Facebook durchaus unfreundliche Bemerkungen über den Vereinspräsidenten $B$ und den von ihm geführten Verein C. Die Einzelheiten sind gänzlich belanglos, die Vorwürfe lassen sich dahingehend zusammenfassen, dass B nazistisches, rassistisches und antisemitisches Gedankengut verbreitet habe, dafür gar wiederholt bestraft worden sei und entsprechend der Verein in die gleiche Kategorie gehöre. Und eigentlich geht es darum, dass die Veranstalter eines bestimmten Ereignisses sich nicht von B und $C$ distanziert haben, sondern sie an eben jene Veranstaltung $\mathrm{Y}$ zugelassen hätten, die doch sonst so viele andere, gänzlich redliche Teilnehmer aufweise. Diese Meldung des «Indyvegan» konnte von einer unbestimmten Vielzahl von Leuten gelesen, kommentiert und weiterverbreitet werden - nur ging es gar nicht darum.

3 Es ging vielmehr um den A: Er verfasste auf demselben «Sozialen Medium», also der Plattform «Facebook», die schon «Indyvegan» gedient hatte, einen (in der Sache zustimmenden) Kommentar zu dem, was Letzterer gesagt hatte, und verwies sodann auf dessen Text durch einen Link.

4 Der Rechtsstreit drehte sich darum, ob dadurch der A die Ehre von B und C verletzt habe.

\section{Ist das Medienstrafrecht auf «Facebook» anwendbar?}

5 Dieser höchst einfache Sachverhalt wird nun unnötig verkompliziert, weil die Verteidigung des A im Strafprozess auf den Gedanken verfiel, das Medienstrafrecht für anwendbar zu halten. Dies wiederum würde heissen: «Facebook» ist ein Medium, und man müsste erwarten, dass das Bundesgericht für diese - neue-Erkenntnis auch eine Begründung liefert. Nur wird die Hauptfrage, ob «Facebook» ein Medium sei, tatsächlich gar nicht beantwortet. Und sie wäre ohnehin mit den von mir in $\mathrm{Zu}-$ sammenhang mit «Twitter» entwickelten Überlegungen zu verneinen: ${ }^{1}$ Die Plattformen der sogenannten «Social Media» sind keine Medien im strafrechtlichen Sinn, und schon gar nicht kann man das Gegenteil (und damit die Anwendbarkeit des Medienstrafrechts) in der Weise begründen, wie es das Bundesgericht vorliegend versucht.

\section{Das geltende Medienstrafrecht}

Machen wir einen kurzen Zwischenhalt: Das Medien- 6 strafrecht beschränkt sich auf ein paar wenige, wenn auch für die Medien und Medienschaffenden wichtige Bestimmungen. Da ist zunächst das in Art. 17 Abs. 3 BV2 verankerte «Redaktionsgeheimnis», das sich auf Gesetzesebene in einer völlig unnötigen Doppelnorm niederschlägt: Praktisch wortgleich enthalten nämlich das Strafgesetzbuch $^{3}$ (Art. 28a) und die Strafprozessordnung 4 (Art. 172) die Bestimmung, dass Medienschaffende über ihre Quellen keine Aussagen als Zeugen machen müssten (jeweils Abs. 1). Dieser Quellenschutz soll erlauben, dass Dritte sich vertrauensvoll an die Medien wenden können, damit diese auf Missstände hinweisen bzw. über die Berichterstattung auf deren Beseitigung hinwirken können. Wären die Medienschaffenden gezwungen, wie jedermann als Zeuge zu erklären, wer ihnen was berichtet hat, woher sie vertrauliche Unterlagen etc. bekommen haben, könnten die Medien die ihnen zugedachte Rolle des «öffentlichen Wachhundes» gar nicht wirksam spielen. Zu diesem von einer reichen Strassburger Rechtsprechung zu Art. 10 EMRK ${ }^{5}$ etablierten Grundsatz gibt es zwei wichtige Ausnahmen: Zum einen kann sich kein Medienschaffender, der selbst angeklagt ist, darauf berufen. Denn der Quellenschutz dient dem Schutz Dritter und enthebt den Medienschaffenden der Zeugnispflicht, nimmt ihm aber nicht die «Last» ab, sich allenfalls durch eigene Beweisführung von einem Vorwurf zu entlasten, insbesondere den Entlastungsbeweis im Ehrverletzungsverfahren zu führen. Und die andere Ausnahme sind die sogenannten «Katalogtaten»: Das ist die Liste der schweren Delikte, bei denen der Quellenschutz nicht gilt, die Ausnahmebestimmung also ausser Kraft gesetzt wird und deshalb wieder die Zeugnispflicht

1 MatThias SCHWAibold, Warum «Twitter» kein Medium im Sinne des Strafrechts ist, sui generis 2017, S.113 ff. - Ich werde auch vorliegend keine "positive» Definition des Mediums liefern können; was aber erneut nicht hindert, ein bestimmtes «Medium» zumindest als keines im Sinne des Strafrechts zu erkennen, und dies zu begründen.

2 Bundesverfassung der Schweizerischen Eidgenossenschaft vom 18. April 1999 (BV; SR101).

3 Schweizerisches Strafgesetzbuch vom 21. Dezember 1937 (StGB; SR311.0).

4 Schweizerische Strafprozessordnung vom 5. Oktober 2007 (Strafprozessordnung, StPO; SR 312.0).

5 Konvention zum Schutze der Menschenrechte und Grundfreiheiten, abgeschlossen in Rom am 4. November 1950 (EMRK; SR 0.101). 
gilt (Art. 28a StGB und 172 StPO, je Abs. 2). Schliesslich besteht das Medienstrafrecht aus einer letzten, hier relevanten Bestimmung: Wird eine strafbare Handlung durch Veröffentlichung in einem Medium begangen und erschöpft sie sich in dieser Veröffentlichung, ist der Autor allein strafbar und niemand sonst (Art. 28 Abs. 1 StGB). Damit werden die allgemeinen Regeln über Mittäterschaft und Teilnahme ausser Kraft gesetzt und nur sehr unvollkommen in den Sonderbestimmungen von Art. 28 Abs. 2 bis 4 bzw. dem Art. 322bis StGB wieder eingefangen. A berief sich auf die Bestimmung des Abs. 1 in der Meinung, er entgehe damit einer Strafbarkeit, weil er ja nur auf den Text des «Indyvegan» verwiesen habe und nichts Relevantes darüber hinaus verbreitet habe als dessen Ansicht. Zudem habe er auf dessen Originaltext verlinkt.

\section{Getümmel in der Sackgasse}

7 Damit wurde die Frage nach einer Ehrverletzung zu einer Frage des Medienstrafrechts, und wenn man sich einmal auf diesen Irrtum eingelassen hat, war ein Entkommen natürlich schwierig: Jetzt verlagerte sich die Diskussion plötzlich darauf, ob die von A und «Indyvegan» gleichermassen benutzte Plattform «Facebook» ein Medium sei. Ohne Medium kein Medienstrafrecht - dieser einfachen Überlegung stimme sogar ich zu.

8 Der ganze Aufwand, der sowohl vom Berner Obergericht wie dann vor allem vom Bundesgericht bezüglich dieser Frage getrieben wird, war völlig unnötig. Nicht nur, weil das Ergebnis auch ohne ihn dasselbe gewesen ist, wie man am Ende sieht, sondern vor allem deshalb, weil er den Blick auf die Bestimmung verdeckt, die für den Ausgang bzw. Fortgang des Verfahrens allein massgeblich ist, nämlich Art. 173 Ziffer 1 Abs. 2 StGB. Dieser stellt die Weiterverbreitung einer Ehrverletzung der ursprünglichen Ehrverletzung gleich. Dass solche Weiterverbreitung vorliegt, kann nicht zweifelhaft sein, und dass in dem Falle dieselben Regeln über den Entlastungsbeweis gelten, auch nicht. Darauf komme ich am Schluss zu sprechen, gleich wie das Bundesgericht, das den Fall an das Berner Obergericht zurückschickt. ${ }^{6}$

\section{Ein verkürzter Problembeschrieb}

9 Warum aber der ganze Umweg über das Medienstrafrecht genommen wird und dabei vieles, das nicht richtig sein kann, erörtert wird, bleibt ein Rätsel, um dessen

6 Urteil des Bundesgerichts 6B_440/2019 vom 18. November 2020 (zur Publikation vorgesehen).
Lösung es vorliegend nicht geht. Ich möchte vielmehr aufzeigen, warum der Weg ein Irrweg, zumindest aber ein Holzweg ist.

Den «Fehler» präsentiert geradezu auf dem Silbertablett 10 die Erwägung 5.4. Die ist so kurz, dass man sie vollständig zitieren kann: «Zunächst setzt Art. 28 StGB voraus, dass die strafbare Handlung «in einem Medium〉 begangen wird.» Das ist nun eine wesentliche, und wie mir scheint unzulässige Verkürzung: Es geht nämlich nicht einfach um «die strafbare Handlung», sondern darum, dass die strafbare Handlung «durch Veröffentlichung in einem Medium» begangen wird, wie in Art. 28 StGB ebenso klar steht. Relevant ist die Tatmodalität «Veröffentlichung» einerseits, der Ort der «Veröffentlichung» andererseits, nämlich «in einem Medium». Man kann beides nicht voneinander trennen, aber das eine folgt nicht aus dem andern. Eine Unterscheidung zwischen «Herstellung und Verbreitung» einerseits und «Veröffentlichung» andererseits trifft dagegen der zum alten Art. 27 StGB ergangene BGE128 IV 53 (dazu unten).

\section{Was ist (k)ein «Medium» im Sinne des Medienstrafrechts?}

Das Bundesgericht zeichnet sodann in Erw. 5.4.1. und 11 5.4.2. in zutreffender Weise die Bedeutung und Entwicklung von Art. 28 StGB und der im wesentlichen Punkt inhaltsgleichen Vorgängernorm (des ursprünglichen Art. 27 StGB) nach. Und weist darauf hin, dass die Reform von 1998 das Ziel verfolgte, von der «Druckerpresse» wegzukommen und den Medienbegriff auf die schon damals nicht mehr neuen, audiovisuellen Medien (Radio und Fernsehen) zu erstrecken, ohne ihn darauf zu beschränken. Die Ausdehnung auf die «neuen Kommunikationsmittel», so die Botschaft, entsprang in erster Linie einem technischen Verständnis. ${ }^{7}$

Die neueste Lehre geht deshalb, vom Bundesgericht 12 zitiert, von einem «weiten Medienbegriff» aus. ${ }^{8}$ Dem

7 Das Bundesgericht verweist in Erw. 5.4.2. auf BBl 1996 IV 525, S. 549 Ziff. 211.11.

8 Z.B. STEFAN TRECHSEL / MARC JEAN-RICHARD-DIT-BRESSEL, in: Trechsel/Pieth (Hrsg.), Schweizerisches Strafgesetzbuch Praxiskommentar, 3. Aufl., Zürich 2017, N3 zu Art. 28 StGB: «Während früher das Privileg auf mit dem `Mittel der Druckerpresse` begangene Straftaten beschränkt war, genügt heute irgendein ‘Medium〉 [Hervorhebung im Original]». Weitgehend WOLFGANG WOHLERS, in: Wohlers/Godenzi/Schlegel (Hrsg.), Schweizerisches Strafgesetzbuch, Handkommentar, 4. Aufl., Bern 2020, N 2 zu Art. 28 StGB: «Unter einem Medium [Hervorhebung im Original] ist, im Einklang mit Art. 17 BV, jedes Mittel zu verstehen, durch das ein gedanklicher oder bildlicher Inhalt einem grösseren, durch persönliche Beziehungen nicht verbundenen Kreis von Personen zugänglich gemacht werden kann (BGE128 IV 65f), also neben allen Arten von Druckschriften in jeder Form der Vervielfältigung auch Radio und Fernsehen, Filme, Ton- und Videoaufnahmen sowie die elektronischen 
schloss und schliesse ich mich erneut an. Wenn die übrige Lehre auch die sog. «Social Media» als Medien anerkennt, scheine ich der einzige zu sein, der diese Auffassung nicht teilt (vgl. die Literaturhinweise in Erw. 5.4.2.). Und daran ist mit Nachdruck festzuhalten: Die «Social Media» sind kein Medium im Sinne des Medienstrafrechts.

\section{Die bundesgerichtliche Exegese zum massgeblichen Medienbegriff, Teil 1}

Das Bundesgericht verwendet in Erw. 5.4.3. dreizehn Sätze mit zahlreichen Literaturhinweisen auf den Medienbegriff des Art. 28 StGB. Ihm ist bezüglich seiner vielfältigen Überlegungen nur teilweise zuzustimmen, und ganz schlecht bestellt ist es um die Qualität oder Kohärenz derselben. Auch wenn es den Leser nachfolgend etwas anstrengt, möchte ich den Text Satz für Satz durchgehen:

Satz1: "Aus dem offenen Wortlaut (‘Medium〉; ‘média〉; (mezzo di comunicazione sociale)) wie auch aus der Botschaft (BBl 1996 549: ‘gesamtmediale Betrachtungsweise〉 im Sinne von aArt. $55^{\text {bis }} \mathrm{BV}^{9}$ ) ergibt sich, dass Art. 28 StGB nicht nur sämtliche Kommunikationsträger (Zeitungen, Zeitschriften, Radio, Fernsehen usw.) sondern auch Kommunikationsmittel (Video, Teletext, Videotext, E-Mail, Internet usw.) erfassen soll.»

Netzwerke mit Einschluss des Internets (BGE 74 IV 131; BGE 78 IV 128; BGE 82 IV 80 = Pra. 1956 Nr. 151; vgl. auch Urteil des Bezirksgerichts Zürich vom 26. Januar 2016, GG150250, E. 4.3 ff = FP 2017, 290 mit Anm. Roth: Twitter als Medium). Zweifelhaft ist die Einordnung von Netzwerken, die eine Individualkommunikation ermöglichen, wie z.B. die Netze der Mobiltelefonie (bejahend Urteil des Obergerichts des Kantons Zürich, SBo60649, E. 5.1 = FP 2008, 271 m. krit. Anm. Riklin). In dieser Weise muss die Veröffentlichung tatsächlich stattgefunden haben, wenn Abs. 1 eingreifen soll (BGE125IV183 f). Keine Rolle spielt, welchen Interessen sie diente (BGE 77 IV 193 f; BGE117 IV 366).» Zu weitgehend dann aber ANDREAS DONATSCH, in: Donatsch/Heimgartner/Isenring/Maurer/Riesen-Kupper/Weder (Hrsg.), StGB/JStG-Kommentar, 20. Aufl., Zürich 2018, N 2 zu Art. 28 StGB: «Als Medien gelten nicht nur das Fernsehen, das Radio sowie die Presse, sondern alle Kommunikationsmittel. Erfasst werden demnach überdies alle Arten von Druckschriften (Blatt, Brief, Bücher, Flugblätter, Plakate, Prospekte, Kataloge etc.), Gemälde, Foto, Film, Kassette, DVD, Videos, der Memory-Stick, die elektronische Textübertragung (Teletext, Videotex, CD-ROM), die telefonische Tonübertragung (Festnetz-, Mobil-, Internet-Telefonie), Mailing-Listen, Newsgroups, der Chat, das Web-Streaming (Ton- oder Bildübertragung via Web) und das World Wide Web. Der Begriff des Mediums ist in einem weiten Sinne zu verstehen (BGE128 IV 65).» Dass das «Internet» ein Medium im Sinne des Strafgesetzbuches sei, ist eine gewiss überschiessende und daher nicht zutreffende Verallgemeinerung; wie hier auch FRANZ ZELLER, in: Niggli/Wiprächtiger (Hrsg.), Strafrecht, Basler Kommentar, 4. Aufl., Basel 2019, N 49 zu Art. 28. Im gleichen Sinne geht zu weit die N14 zu Art. 28 im Commentaire Romand von ROTH/MOREILLON, während der Petit Commentaire von DUPUIS ET AL. in seiner N 4 zu Art. 28 StGB unentschieden bleibt. - Dass «Facebook» ein solches Medium sei, wird zudem von keinem der sechs Kommentare ausdrücklich gesagt, auch nicht von ZELLER, der «Facebook» als einziger explizit in seinen Noten 52a und 118a benennt.

9 Bundesverfassung der Schweizerischen Eidgenossenschaft vom 29. Mai 1874 (aBV; SR101).
Satz 2: "Die offene Formulierung ist aufdas Bestreben des Gesetzgebers zurückzuführen, die Medienlandschaft in ihrer gesamten Vielfalt zu erfassen (BBl 1996526 ff.; Protokoll der Sitzung der Kommission für Rechtsfragen des Ständerats vom 14./15. Mai 1997, S. 3f.; AB 1997 S 573f.; AB 1997N389f.).»

Zweifeln begegnet schon der Satz1, wonach der weite 14 Medienbegriff nicht nur «Kommunikationsträger», sondern auch die «Kommunikationsmittel» umfassen soll. Und nicht etwa einige, sondern «sämtliche». Die Unterscheidung und die Zuteilung gewisser Erscheinungsformen unter die beiden vorgenannten Kategorien ist durchaus fraglich: So sollen «Zeitungen, Zeitschriften, Radio, Fernsehen usw.» Kommunikationsträger sein; dagegen seien «Video, Teletext, Videotext, E-Mail, Internet usw.» Kommunikationsmittel. ${ }^{10}$ Damit führt man unerklärt einen neuen Begriff ein - die «Kommunikation». Und aus dieser Gesamtheit wird in Satz 2 die «Medienlandschaft in ihrer ganzen Vielfalt». Also sind Medien, Kommunikationsträger, Kommunikationsmittel nur Teile eines grösseren Ganzen, ohne dass wir erfahren würden, ob und gegebenenfalls was es in dieser «Medienlandschaft» noch anderes gäbe. Denn weder die «Medien» noch die «Medienlandschaft» werden ohne zusätzliche Erklärung - eine solche fehlt aber - dadurch erfassbar, dass man Medien plötzlich in «Kommunikationsträger» und «Kommunikationsmittel» aufteilt und aus unbestritten «klassischen» Medien wie den gedruckten und audiovisuellen die dem Gesetz fremde Kategorie der «Kommunikationsträger» bildet. Jedenfalls wäre zu erklären - was ebenso unterbleibt -, warum ein «Video» lediglich ein «Kommunikationsmittel» sein soll. Spinnen wir den Gedanken kurz fort: Auch der Brief, das Telefon und der längst verschwundene Telegraf bzw. das Telegramm sind zugleich «Kommunikationsmittel» wie «Kommunikationsträger», gleich wie das Buch, ohne dass sie alle vom Bundesgericht auch nur erwähnt würden oder man in der Vergangenheit auf die Idee gekommen wäre, auf sie das «Medienstrafrecht» anzuwenden.

Satz 3: «Freilich konnte der Gesetzgeber damals - an der Schwelle zum Informationszeitalter - nicht voraussehen, dass sich die Grenze zwischen Produzenten- und Konsumentenrolle bei der medialen Kommunikation in gewissen Bereichen nicht mehr leichthin ziehen lässt.»

Der Rechtshistoriker weiss längst, dass noch kein Gesetz- 15 geber die Zukunft gekannt hat und sein Werk immer von der Zeit und ihren Werken überlagert wird; das ist im

10 Diese Kategorisierung lässt sich insbesondere nicht mit der Botschaft des Bundesrats, BBl 1996 IV 525, S. 549 begründen, die zwischen «Druckschriften» (zu welchen sie namentlich Zeitungen und Zeitschriften zählte) und «elektronischer Textübertragung = elektronischer Textkommunikation» (zu welchen Teletext und Videotext gezählt wurden) unterschied. 
Medienstrafrecht nicht anders, aber für das Strafrecht wegen des gegenüber den meisten anderen Rechtsgebieten strengeren Gesetzesvorbehalts und des Analogieverbots vielleicht noch wichtiger. Indessen kommen «Produzent» und «Konsument», bzw. die jeweilige «Rolle» weder im Gesetz vor noch hat sich der Gesetzgeber damit einlässlich befasst. Aber wir haben schon im dritten Satz die nächste, nicht eingeführte Kategorie, nämlich zwei gemäss Wortsinn eigentlich antagonistische «Rollen», die sich nicht klar abgrenzen liessen. Und wir stossen auf die «mediale Kommunikation», ohne dass wir mit diesem wiederum neuen Begriff etwas anfangen können: Geht es dabei jetzt um Medien oder um Kommunikation, und was ist die «mediale» Kommunikation im Unterschied zu welchen anderen Arten der Kommunikation?

Satz 4: "SCHWARZENEGGER weist zutreffend darauf hin, dass heutejede Person auf eine Produktionsstättefür Medienveröffentlichungen) zurückgreifen kann (SCHWARZENEGGER, Anwendungsbereich, a.a.O., S.171; vgl. auch Eidg. Justiz- und Polizeide partement, Bericht der Expertenkommission «Netzwerkkriminalität〉, 2003, S. 62f.; Rechtliche Basis für Social Media: Erneute Standortbestimmung, Nachfolgebericht des Bundesrates zum Postulatsbericht Amherd 11.3912 «Rechtliche Basis für Social Media> vom 10. Mai 2017, S. 7ff.).»

16 Nahtlos geht das Bundesgericht aus Satz 3 mit Satz 4 zum nächsten Gedanken über, den es aus einer Veröffentlichung von CHRISTIAN SCHWARZENEGGER übernimmt: Es seien nicht nur die Grenzen von «Produzenten- und Konsumentenrolle» nicht mehr so leicht zu ziehen, ebenso könne jeder auf eine «Produktionsstätte für Medienveröffentlichungen zugreifen». Aber wozu diese Betrachtung? Es geht nämlich in diesem Satz, wiederum uneingeführt, um «Medienveröffentlichungen» und deren Herstellung. Selbst wenn wir annehmen wollten, Sätze 3 und 4 seien richtig, führen sie doch nur weiter in die Irre: Wie sind «Medienveröffentlichungen» denn von den «Kommunikationsträgern» und/oder den «Kommunikationsmitteln» zu unterscheiden? Was ist jetzt für den strafrechtlichen Begriff des «Mediums» eigentlich konstitutiv und was nicht? Die Produktionsstätte, die Medienveröffentlichung, die Rollen, die Kommunikationsträger oder die Kommunikationsmittel? Die Frage wird weder aufgeworfen noch beantwortet, aber sie ergibt sich meines Erachtens zwingend, wenn die bundesgerichtliche Darlegung konsistent sein soll. Was sie indessen nicht ist.

Denn übergangslos folgt die nächste Überlegung:

Satz 5: "Dass der Gesetzgeber Art. 28 StGB auf Formen direkter Kommunikation ausdehnen wollte, lässt sich den Materialien nicht entnehmen und widerspräche der ratio legis (kritisch auch ZELLER, a.a.O., N. 44 zu Art. 28 StGB; SCHWAIBOLD, a.a.O., S.116ff.; WOHLERS, a.a.O., N. 2 zu Art.28StGB).»

Diese Ansicht trifft zu, wenn auch nicht deshalb, weil sie 18 neben zwei weiteren Autoren auch mir zugebilligt wird. ${ }^{11}$ Sie hat auch gar nichts mit der Frage von Produzentenoder Konsumentenrolle und allen anderen in den vier Sätzen zuvor gefallenen Begriffen zu tun. Wenn aber die «direkte Kommunikation» etwas anderes sein soll als der strafrechtliche Medienbegriff, so haben wir mit diesem Satz zumindest ein negatives Abgrenzungskriterium entdeckt: Direkte Kommunikation ist jedenfalls nicht «Medium», umgekehrt muss «Medium» etwas sein, was nicht «direkte Kommunikation» ist. Darauf ist zurückzukommen.

Das Bundesgericht fährt, ohne sich dabei aufzuhalten, 19 mit einer doppelten Behauptung fort:

Satz 6: «Umgekehrt können Social Media nicht als blosse Form der Individualkommunikation bezeichnet werden (so aber SCHWAIBOLD, a.a.O., S.126f.).»

Es widerspricht damit der (angeblich nur von mir) ver- 20 tretenen Ansicht, ohne allerdings eine Begründung zu liefern. ${ }^{2}$ Zudem habe ich es in dieser Weise gar nicht formuliert, man findet bei mir keinen Satz, der lauten würde, «Social Media sind lediglich Formen der Individualkommunikation» oder ähnlich. Ich gebe allerdings zu: Als blosse Zusammenfassung meiner Ansicht über Plattformen wie Twitter (zu der ich mich geäussert hatte) oder Facebook würde ich den Satz tatsächlich gelten lassen. Wichtig an dem Satz ist indessen nur, dass er einen weiteren Begriff einführt - nämlich die «Individualkommunikation». Wie sie indessen in den Begriffswald der fünf vorangehenden Sätze einzugliedern wäre, erfahren wir dann auch nicht.

Denn das Bundesgericht gelangt übergangslos zur 21 nächsten Ausschluss-Überlegung:

Satz 7: «Auch lässt sich die Anwendbarkeit von Art. 28 StGB nicht generell aufjene Berufskategorien (Redaktoren, Verleger, Drucker) beschränken, wie sie in der früheren Gesetzesfassung privilegiert wurden (so aber Franz Riklin, Kaskadenhaftung - quo vadis?, Medialex 2000 S. 206).»

11 Das Bundesgericht bezieht sich auf meinen in Fn. 1 erwähnten Bei trag in sui generis 2017, S.113 ff.

12 Dabei stimmt mir FRANZ ZELLER in N 44 zu Art. 28 im BSK StGB ausdrücklich unter Hinweis auf den genannten Beitrag zu, indem er die Ausdehnung des Medienbegriffs auf Formen der direkten Kommunikation ablehnt. 

nichts mit der (zumal für die Vergangenheit zutreffenden) des hochgeachteten Kollegen RIKLIN zu tun, aber gemeinsam trifft uns das Verdikt aus Lausanne:

\section{Satz 8: «Beide Ansätze greifen zu kurz.»}

Nun, ich habe mich (angeblich) über die Individualkommunikation geäussert, FRANZ RIKLIN über bestimmte Berufsgruppen. Worin genau unser «Zu-kurz-Greifen» bestanden hat, wird nicht erläutert und erschliesst sich zumindest mir nur in Bezug auf Riklin: Er hatte auf die Beteiligten an klassischen Druckmedien Bezug genommen, was in einem Aufsatz aus 2000 niemandem zum Vorwurf gereichen kann, wenn es um den Medienbegriff geht. Dass es bei den «sozialen Medien» modernsten $\mathrm{Zu}$ schnitts keine Drucker und eigentlich auch keine Verleger gibt, Redaktoren schon gar nicht - ausser man würde damit jeden Verfasser eines Textes bezeichnen wollen - macht Riklins Ansatz nicht einfach irrelevant oder auch nur «zu kurz».13

Satz 9: «Denn das Medienprivileg gilt für alle Personen, die an der Herstellung oder Verbreitung eines Medienerzeugnisses mitwirken.»

\section{Berufskategorien, fort:}

Satz 10: «Sie müssen - anders als beim ‘periodischerscheinenden Medium nach Art. 28 a Abs. 1 StGB oder beim «Medienunternehmen> nach Art. 322 Abs. 1 StGB - nicht Teil eines Medienunternehmens sein (BGE128IV53 E. 5e partie d'une entreprise de media); Zeller, a.a.O., N. 47 zu Art.28StGB; Trechsel/Jean-Richard, a.a.O., N.3zuArt. 28 StGB; a.A. Riklin, Kaskadenhaftung, a.a.O.S. 206; Schwarzenegger, Anwendungsbereich, a.a.O., S. 187).»

13 Völlig zutreffend deshalb FRANZ ZELLER (Fn.7), N 24 zu Art. 28 StGB: Es «lassen sich die Abläufe und Zuständigkeiten bei Veröffentlichungen durch die herkömmliche Druckerpresse nur bedingt auf heutige Publikationen in der Online-Welt übertragen (...).»; ähnlich sodann erneut in $\mathrm{N} 44$.
Damit wird, ohne dass es vertieft würde, eine weitere 26 Unterscheidung eingeführt: Dass es nämlich zwischen Art. 28 und Art. 28a Abs. 1 StGB einen relevanten Unterschied gäbe: Der Quellenschutz ist offenbar enger zu verstehen (weil auf «periodische Medien» beschränkt) als die ausschliessliche Haftbarkeit des Autors. Aber was ist daraus für den Medienbegriff des Art. 28 abzuleiten? Jedenfalls nichts, was das Bundesgericht erklären würde.

Denn es fährt bei seiner rein «personalen» Überlegung 27 aus Satz 9 und 10 mit Satz11 fort:

\section{Satz 11: «Dies ist historisch zu begründen.»}

Diese «historische Begründung» fällt dann aber gar kurz 28 aus:

Satz 12: «Denn bereits aArt. 27 Abs. 2 StGB (in Kraft ab 1.Januar 1942; AS 54 757) regelte ausdrücklich die Verantwortlichkeit bei «nicht periodischen Druckschriften, namentlich die Publikation eines Inserats im Anzeigeteil einer Zeitung durch Aussenstehende (BBl 1918IV 11; Carl Ludwig, Schweizerisches Presserecht, 1964, S.156f.).»

Diese Behauptung ist so nicht zutreffend, denn der Ver- 29 fasser des Bundesgerichtsurteils hat offenbar nicht den Originaltext des alten Art. 27 Abs. 2 StGB gelesen, der keineswegs vom Inserat handelt, das in diesem Absatz 2 gar nicht vorkommt: Der handelt vielmehr in seinem deutschen Text von den «nicht periodischen Druckschriften», französisch im Singular dem «imprimé non périodique». Diese bilden den Gegensatz zu dem, was in Abs. 1 als «Presserzeugnis» der «Druckerpresse» entsprungen war, französisch «par la voie de la presse» zu einer «publication» führte. Und wie regelte Abs. 2 die Verantwortlichkeit? Indem im Fall der nichtperiodischen Publikation gleich wie in Abs. 1 der Autor haftet; er haftet gemäss Abs. 2 nur dann nicht, wenn er nicht gefunden wird oder die Veröffentlichung ohne sein Wissen, gar gegen seinen Willen erfolgte; dann haften an seiner Stelle der Herausgeber oder, wenn auch der nicht auffindbar ist, gar der Drucker anstelle des Autors. Vergleichbar dann in Abs. 3 die Regelung, die inhaltlich an den Abs. 1 anschliesst, und erst in Abs. 4 die Regelung über die Inserate. Mithin haftete nach dem ursprünglichen Gesetzeswortlaut immer der (bekannte) Autor bzw. Einsender. Aber für die Definition des modernen, für das geltende Strafrecht massgeblichen Medienbegriffs ist doch damit überhaupt nichts gewonnen: Aus der Haftungsordnung folgt doch nichts für deren Voraussetzung, das «Medium», sondern dieses ist umgekehrt Voraussetzung für die Haftungsordnung, eben die Privilegierung von Teilnehmern.

Schon gar nicht lässt sich der Schlusssatz damit recht- 30 fertigen oder wenigstens verknüpfen: 
Satz 13: «Insofern sollen alle Personen über diePresse bzw. heute über ein (Medium) ihre Meinung in der Öffentlichkeit möglichst wirksam zur Geltung bringen können.» «Meinungen» und diese auch noch «wirksam» zur Geltung bringt, sondern ob man etwas in besonderer Weise veröffentlicht - nämlich «in einem Medium». Die verfassungs- und menschenrechtlich garantierte Meinungsfreiheit bezieht sich nicht darauf, ob eine «Meinung» (oder was auch immer) über ein Medium oder ein Nichtmedium geäussert wird. Die einzige Folge des Art. 28 StGB ist - seine Anwendbarkeit vorausgesetzt!-, dass eine Äusserungsmodalität allenfalls bestimmte Handlungen ausser Strafe stellt. Zudem stellt der Satz des Bundesgerichts den Regelungsgehalt von Art. 28 StGB noch auf den Kopf: Wer seine Meinung in einem Medium äussert, ist Autor und deshalb dafür haftbar; das darin enthaltene Privileg gilt nicht dem Autor, sondern seinen allenfalls vorhandenen Helfern.

32 Wir haben es in der Erw. 5.4.3. mit einer leider typischen Art der Begründung zu tun: 13 Sätze, die durch keinerlei roten Faden verbunden sind, von Thema zu Thema springen, zwar Belegstellen anführen, aber nicht erklären, was zu erklären ist: Wie ist der Medienbegriff des Art. 28 StGB zu verstehen, vor allem: Was unterscheidet «Medien» von «Kommunikation»? Wir erfahren es nicht.

\section{Die bundesgerichtliche Exegese zum massgeblichen Medienbegriff, Teil 2}

33 Diese durchaus unbefriedigende Form der Argumentation setzt sich dann in Erw. 5.4.4. fort, die den «sozialen Medien» gewidmet ist. Daraus ist zunächst nur wichtig Satz 3: «Die Weite des Medienbegriffs führt allerdings nicht dazu, Social Media gemeinhin als «Medium` zu qualifizieren.» Versuchen wir, diesen Satz 3 mit dem Satz 6 aus der Erw. 5.4.3. unter einen Hut zu bringen: Einerseits seien sie nicht blosse Formen der Individualkommunikation, hiess es dort und gegen meine Ansicht. Andererseits sind sie nicht "gemeinhin» Medium. Ja was sind sie dann bzw. was ist ein Medium? Die Antwort bleibt natürlich aus. Soziale Medien sind also auch, aber nicht nur (wie von mir behauptet!) Formen der Individualkommunikation, sie sind unter Umständen, aber eben nicht von vorneherein («gemeinhin») Medium. Also können sie beides sein. Wichtig wäre aber doch zu wissen, ob sie jetzt Medien sind oder nicht. Statt einer klaren Antwort kommt mit Satz 4 die fatale Formel, die eigentlich ersatzlos an die Stelle der gesamten Erwägungen 5.4.1 bis 5.4.4. hätte treten können: «Vielmehr ergibt sich die konkrete Anwendbarkeit von Art. 28 StGB im
Einzelfall aus dem Erfordernis, dass das Medienerzeugnis der Öffentlichkeit zugänglich gemacht wird.» Lassen wir die beckmesserische Bemerkung stehen, dass «Medium» und «Medienerzeugnis» an dieser Stelle einfach gleichgesetzt werden. Und halten wir fest, dass es plötzlich und ohne jede argumentative Vorankündigung auf die «Öffentlichkeit» der Mitteilung ankommt. Nur nochmals: Veröffentlicht wird auch ein Buch, und «veröffentlicht» ist auch eine Ehrverletzung, die in einer Volksversammlung erfolgt. Wir haben also für den Medienbegriff nichts gewonnen, schon gar nicht in Bezug auf «Social Media». Wir erfahren einzig, dass die Anwendbarkeit des Art. 28 StGB ein Medienerzeugnis und eine Veröffentlichung voraussetze. Das führt uns aber an den Anfang zurück, ohne dass wir eine Antwort bekommen hätten. Vermutlich liegt in dieser Art der Argumentation eine Tautologie vor, aber ich lasse das offen. Sie ist, und das lasse ich nicht offen, in höchstem Masse unbefriedigend.

\section{Verwechslung von Ursache und Folge}

Erw. 5.5. schwenkt dann zu einem weiteren Problem: 34 der «für das Medium typischen Herstellungs- und Verbreitungskette». Die ist deshalb von Belang, weil die Anwendbarkeit von Art. 28 StGB zu einer Privilegierung derer führt, die in dieser «Kette» stehen, ohne Autor zu sein - denn sie haften nicht, nur der Autor. Allerdings haben wir auch hier ein logisches Problem: Die Frage nach der «Kette» stellt sich doch nur, wenn zuvor die Frage nach dem «Medium» positiv beantwortet worden wäre, also feststeht, dass es überhaupt einen Anwendungsfall von Art. 28 StGB gibt. Der lässt sich nicht aus der Existenz einer «Kette» ableiten, sondern bildet die Voraussetzung dafür, bei einem «Kettenmitglied», um es so zu formulieren, die Frage nach der Haftung (oder eben Nichthaftung) beantworten zu können. Fehlt es am «Medium», stellt sich die Frage gar nicht, weil es dann allein auf die Frage einer (Mit-)Täterschaft ankommt, sich die Problematik einer «Privilegierung» von vorne herein nicht stellen kann. Das Bundesgericht beruft sich auf zwei Entscheidungen. Der ältere von beiden, BGE 86 IV 145, enthält folgende grundsätzlich weittragende Erw. 1: «Art. 27 StGB schliesst, wenn der Verfasser eines ehrenrührigen Zeitungsartikels bekannt ist, die Bestrafung der nicht im Druckereigewerbe tätigen Personen, die nach den allgemeinen Vorschriften des StGB als Mittäter, Anstifter oder Gehilfe des Verfassers mitverantwortlich sind, nicht aus (BGE 73 IV 67). Egger, der als Musiklehrer dem Verfasser des eingeklagten Zeitungsartikels die Unterlagen verschafft und bei der Veröffentlichung mitgewirkt hat, fällt als Mittäter oder als Teilnehmer an der Schmid zur Last gelegten Ehrverletzung in Betracht. Er ist daher Beteiligter im Sinne von 
Art. 30 StGB.» Allerdings blieb diese Erwägung 1 für den damaligen Entscheid irrelevant: Der Informant Egger war gar nicht angeklagt; und weil ihm gegenüber kein Strafantrag gestellt worden war, vielmehr auf einen solchen sogar ausdrücklich verzichtet wurde, wurde der (einzig) angeklagte Journalist Schmid auch freigesprochen, welchen Freispruch das Bundesgericht durch Abweisung der Nichtigkeitsbeschwerde des Privatklägers bestätigte (Unteilbarkeit des Strafantrags). Abgesehen davon ist dieser Entscheid ein Beleg dafür, dass der zuvor kritisierte Riklin mit seiner «personalen» Betrachtung des Medienprivilegs eben auf solider Grundlage aufgebaut hatte.

Sehr viel einschlägiger ist dagegen der jüngere, aber ebenfalls noch zum (alten) Art.27 StGB ergangene BGE128IV 53, Erw. 5.e. Dort spricht das Bundesgericht vom "pressemässigen Mitwirken» und der «chaîne de production et de diffusion», welche über die Tragweite des Haftungsprivilegs entscheide. Aber eben: Vorausgegangen war auch hier die Bejahung der Ausgangsfrage, dass ein (politisches) Plakat ein «Medium» im Sinne der Strafbestimmung sei. Genau diese Frage hat aber der Facebook-Entscheid bisher nicht beantwortet. Wir lesen vielmehr folgenden, erstaunlichen Schlusssatz: «Insofern wird zwar der Verbreiter, nicht aber der Weiterverbreiter nach Art.173 StGB von Art. 28 StGB erfasst. Der weite Medienbegriff bedingt, dass im Einzelfall geprüft werden muss, wer Teil der medientypischen Herstellungs- und Verbreitungskette ist.» Jetzt wird also plötzlich zwischen «Verbreitung» und «Weiterverbreitung» unterschieden, und diese Unterscheidung soll wiederum darüber entscheiden, ob ein Medium vorliegt. Ich glaube, spätestens an dieser Stelle ist die Tautologie erreicht.

\section{$X$. Ein Schluss, der keiner ist}

Und damit sind wir an der inhaltlichen Schlusserwägung 5.6. angelangt. Sie sei vollständig zitiert:

Satz1: «Bei Facebook handelt es sich um einen sozialen Netzwerkdienst, der darauf ausgerichtet ist, eine schnelle und weitreichende Kommunikation zu ermöglichen (BGE146IV23 E. 2.2.3 mit Hinweis).»

Satz 2: "Der auf Facebook aufgeschaltete Beitrag des Beschwerdeführers richtete sich an ungefähr 2'500 Personen.»

Satz 3: «Der Beschwerdeführer hat folglich einem breiten Personenkreis die Möglichkeit der Kenntnisnahme eröffnet.»

Satz 4: «Ob der Beitrag tatsächlich zur Kenntnis genommen wurde, ist bei der Veröffentlichung im Sinnevon Art. 28
StGB nicht von Bedeutung (Donatsch/Tag, a.a.O., S. 205; Schwarzenegger, Anwendungsbereich, a.a.O., S.177).»

Satz 5: «Das 〈Teilen〉 des Artikels von 〈Indyvegan〉 auf Facebook als Medium steht der Anwendung von Art. 28 StGB daher im vorliegenden Fall nicht entgegen.»

Satz 6: «Entscheidendistjedoch die Frage, ob sich der Beschwerdeführernoch innerhalb der medientypischen Herstellungs- und Verbreitungskette bewegte.»

Satz 7: «Dies ist zu verneinen.»

Satz 8: "Der Ausgangsartikel wurde mit dem entsprechenden 〈Post〉 von ‘Indyvegan〉 in Verkehr gesetzt und stand damit nicht mehr unter der Kontrolle des Herstellers.»

Satz 9: «Mit dem 〈Teilen〉 wurde lediglich ein fremder bereits veröffentlichter Beitrag verlinkt.»

Satz10: «Der Rechtsstandpunkt der Vorinstanz erweist sich damit als zutreffend.»

Satz 11: «Eine privilegierte Teilnahme im Sinne von Art. 28 StGBfällt ausser Betracht.»

Was ersehen wir daraus? Erneut behellige ich die Leser- 37 schaft mit einer Satz-für-Satz-Kritik, weil auch diese Erwägung keinerlei Konsistenz aufweist:

Facebook ist gemäss dem ersten Satz ein Kommunikati- 38 onsmittel. Im zum Beleg zitierten Entscheid, bei dem es letztlich um einen Parallelfall ging, weil es um vergleichbare Äusserungen über denselben Verein und seinen Präsidenten ging, hielt das Bundesgericht nur fest, dass Facebook der schnellen Kommunikation diene. Keine Silbe dazu, ob es sich um ein «Medium» im Sinne des Medienstrafrechts handle. Da es sich dabei um eine Frage des Bundesrechts handelt, hätte das Bundesgericht von sich aus die Frage aufgreifen müssen, wenn es das Problem gesehen hätte; es muss nicht durch Parteivorbringen auf die Existenz und den Inhalt des Art. 28 StGB hingewiesen werden. Da weder Bundesgericht noch die Vorinstanzen einen Gedanken auf das Medienstrafrecht in jenem Fall verschwendet haben, ist allein schon daraus eher ein Argument gegen Facebook als Medium zu ziehen als dafür.

Die Feststellung in Satz 2, dass der inkriminierte Beitrag 39 des A von rund 2'500 Facebook-Nutzern gelesen werden konnte, stellt lediglich ausser Zweifel, dass es hier um eine Veröffentlichung bzw. eine Äusserung gegenüber Dritten ging. Für die Frage der Medieneigenschaft von Facebook ist damit indessen nichts gewonnen, zumal Satz 2 auch sonst nicht an den Inhalt von Satz 1 anschliesst. 
Wenigstens schliesst Satz 3 an Satz 2 an, indem er festhält, viele hätten den Beitrag zur Kenntnis nehmen können. Das ist indessen bei einer Veröffentlichung auch kein Wunder.

In Satz 4 wird dann festgehalten, es käme für die Anwendbarkeit von Art. 28 StGB aber nicht darauf an, ob der Artikel tatsächlich «zur Kenntnis genommen» worden sei. Das ist eine Feststellung ohne Grundlegung. Denn zu klären ist, ob Art. 28 StGB überhaupt anwendbar sei. Bekanntlich haben wir darauf keine Antwort bekommen. Es wird damit an den Art. 28 StGB eine Frage herangetragen, die tatsächlich nichts mit ihm zu tun hat, aber so klingt, als könnte er vorliegend anwendbar sein. auf das zu enthalten scheint, was viele Sätze und Worte zuvor umhergeschoben wurde: Der Anwendung von Art. 28 stehe etwas nicht entgegen - was ausgedeutscht heisst, Art. 28 sei trotz «etwas» anwendbar. Aber was ist dieses offensichtlich entscheidende «Etwas», das nicht hindert? Es ist das «Teilen» des Artikels auf Facebook als Medium. Weil man also auf Facebook etwas teilen kann, ist es ein Medium - zumindest ist man versucht, das als logische Folgerung aus diesem Satz abzuleiten. Man kann auch einen Brief kopieren oder einen Beipackzettel eines Medikaments und weiterverteilen - das macht indessen weder das eine noch das andere zu einem «Medium». Auch jede E-Mail von X an Y kann Y an unendlich viele E-Mail-Adressen weiterleiten, ohne dass damit die E-Mail oder gar deren Inhalt zu einem «Medium» im Sinne des Medienstrafrechts werden könnten, meine ich.

42 Aber diese Möglichkeit des «Teilen-Könnens» ist dann doch wieder nicht entscheidend, wenn wir Satz 6 lesen, gemäss dem es auf die «medientypische Herstellungsund Verbreitungskette» ankommt. Aber sie ist allein entscheidend für die Frage der Privilegierung, sie kann deshalb nicht auch noch entscheidend dafür sein, ob bzw. dass Art. 28 StGB anwendbar ist. Die Privilegierung ist, nur die Folge der Anwendbarkeit, und weder sie noch die «Kette» können die Anwendbarkeit begründen, sondern setzen sie voraus. Mithin bekommen wir in den Sätzen 5 und 6 völlig inkohärente, um nicht zu sagen widersprüchliche Botschaften, die selbst dann zu kritisieren sind, wenn man sie als widerspruchsfrei erachten wollte: Der Grundmangel, dass über den Medienbegriff keine Klarheit geschaffen wird und die Anwendbarkeit des Art. 28 StGB die Voraussetzung dafür ist, über die Privilegierung und die medientypische Verbreitungskette überhaupt nachzudenken, wird damit nicht behoben.

43 Der ganze Luftballon platzt mit Satz 7: Der Angeklagte A stünde eben ausserhalb dieser Verbreitungskette. Also ist das ganze bis dahin aufgeführte «Theater» um den
Art. 28 StGB doch unnötig gewesen, wenn er - wäre er anwendbar gewesen - dann gerade doch nicht anwendbar ist.

Und so sind wir gespannt auf die Begründung, die doch 44 spätestens jetzt umfangreich und gründlich folgen müsste. Sie besteht formal aus vier überwiegend kurzen Sätzen, von denen lediglich die zwei ersten, die Sätze 8 und 9, überhaupt relevant sind. Satz 8 besagt, dass der «Indyvegan» genannte Facebook-Nutzer den (seinen?) Artikel in Verkehr gesetzt habe und mit diesem «Post» (bzw. «posten» oder «Posting») der «Hersteller» die Kontrolle darüber verloren habe. Das ist nichts anderes als das Bild vom abgeschossenen Pfeil, den man nicht zurückholen kann, oder eben von der fatalerweise an die falsche Adresse geschickte Mail oder SMS mit verfänglichen Inhalten. Aber begründet dieser «Kontrollverlust» die Medieneigenschaft von Facebook? Doch sicher nicht. Und was hat das vor allem mit A zu tun? Natürlich nichts, denn was «Indyvegan» gemacht hat, ermöglichte dem A allenfalls etwas, was sonst nicht oder nur auf Umwegen möglich gewesen wäre: Ohne den «Post» hätte A den Artikel nicht gekannt bzw. zur Kenntnis nehmen können, er hätte ihn auch nicht weiterleiten oder kommentieren können, er hätte aber beides, eines von beiden oder überhaupt die Kenntnisnahme des Artikels unterlassen können. Die Handlung von «Indyvegan» ist, haftungsrechtlich gesehen, natürlich kausal für das Handeln von A, aber das ist auch schon alles. Dass die Handlung von «Indyvegan» Facebook zum Medium mache, sagt das Bundesgericht gerade nicht.

Also bleibt als letzte (logische) Hoffnung, dass die Hand- 45 lung des A begründen könnte, dass Facebook ein Medium ist. Aber auch daran fehlt es, es gibt keine positive, klare Aussage in diesem Sinne.

Denn Satz 9 handelt vom «Teilen» des Artikels, mithin 46 der Handlung des A. Dieses Teilen sei lediglich das Verlinken eines fremden, bereits publizierten Beitrags. Was durchaus zutrifft und insoweit auch weder neu noch überraschend ist, bloss wüsste man gerne, was dieses «Teilen» für eine Bedeutung hat. Das Bundesgericht sagt es uns leider nicht. Das ist mit allem Nachdruck zu kritisieren. Es bleibt völlig unklar, ob jetzt Facebook ein «Medium» im Sinne des Art. 28 StGB sei und warum, es bleibt lediglich der Befund, dass dem A vorgehalten wird, er könne sich nicht auf das darin enthaltene Haftungsprivileg berufen. Beides wäre einlässlich zu erklären gewesen. Nichts von beidem wird erklärt.

Stattdessen erklärt es den «Rechtsstandpunkt» der Vor- 47 instanz für zutreffend (Satz 10) und schliesst mit Satz11 eine privilegierte Teilnahme des A im Sinne von Art. 28 StGB aus. 


\section{Eckpunkte exakter Exegese} letzung begangen hat. Ich sage das mit dem ausdrücklichen Vorbehalt, dass meine eigene strafrechtliche Einschätzung dazu eine andere ist und zumindest der Entlastungsbeweis als gelungen zu betrachten wäre, aber das ist nicht das Thema.

51 Wenn «Indyvegan» sich in strafbarer Weise in seinem Artikel geäussert hat, dann ist er als Verfasser dieser Äusserung auch haftbar, und zwar völlig unabhängig davon, ob er sich in einem «Medium» gemäss Art. 28 StGB geäussert hat oder nicht. Wenn er sich in einem «Medium» geäussert haben sollte, wäre allenfalls noch als Nebenfrage zu prüfen, ob sich in der Publikation die strafbare Tat «erschöpft» hat. Davon wäre, so meine ich, ohne Zweifel auszugehen.

52 Für die Strafbarkeit des A kommt es dann aber entscheidend darauf an, ob «Facebook» ein Medium ist. Nur dann sind Überlegungen zur «Verbreitungskette» und zur Privilegierung des A sinnvoll; ist Facebook kein Medium, fehlt es an der Grundvoraussetzung, über die Verbreitungskette und die damit verbundene Privilegierung des A überhaupt nachzudenken, und es gelten für A die ganz normalen Regeln der Weiterverbreitung einer Ehrverletzung.

53 Also hätte sich das Bundesgericht einlässlich und gründlich mit der Frage auseinandersetzen müssen, ob Facebook ein Medium sei; es kann diese Frage nicht einfach offen lassen oder gar das in jedem Einzelfall neu entscheiden wollen, so scheint es aber tatsächlich zu überlegen (Satz 4 von Erw. 5.4.4., oben VIII). Denn gleich wie es keinen Zweifel geben konnte, dass eine Zeitung oder Zeitschrift ein Medium im Sinne von aArt. 27 bzw. dann Art. 28 StGB ist, kann die Frage nicht in jedem Einzelfall neu entschieden werden und einmal die NZZ, der TagesAnzeiger oder die Weltwoche ein Medium sein und ein anderes Mal nicht. Warum das bei Facebook anders sein soll, wäre wenigstens zu erklären. Facebook ist lange genug auf dem Markt und seine Funktionsweise hinlänglich bekannt, um seinen Charakter als Medium nunmehr klären zu können, jedenfalls solange es nach dem (ohnehin seit jeher grundsätzlich gleichen) bekannten Muster funktioniert.

Dass man damit bei der Auslegung des bewusst offenen, 54 unbestreitbar unbestimmten und sicher nie abschliessend zu umschreibenden Begriffs «Medium» angekommen ist, bestreite ich gar nicht. Das ist vielmehr die ureigenste Aufgabe des Bundesgerichts als der wichtigsten Institution unserer Rechtsfortbildung. Aber diese Aufgabe muss es auch erfüllen, und das verlangt die Beachtung gewisser handwerklicher und intellektueller (dogmatischer) Ansprüche. Denen wird das Urteil nicht ansatzweise gerecht.

Ein unangreifbarer Ansatz hätte darin bestehen können, 55 von den bisherigen Medien auszugehen, die für sie typischen Herstellungs- und Verbreitungsketten darzulegen und sich dann zu fragen, ob daraus etwas für Facebook zu gewinnen sei. Zudem hätte man die nur folgenlos angedeutete Unterscheidung von «Medien» und «Kommunikation» näher untersuchen können. Man wäre, dessen bin ich sicher, auf beiden Wegen zum selben Ergebnis gekommen, nämlich dass Facebook kein Medium ist. ${ }^{14}$ Schliesslich hätte man in einem dritten Schritt die (wesentliche) Funktionsweise von Facebook schildern müssen; dazu hätte gehört, die Funktionen des «Teilens» und «Postens» eines Beitrags klarzustellen und zu erläutern, warum das blosse «Teilen» nicht Teil der typischen Herstellungs- und Verbreitungskette ist, und ob oder warum das «Posten» eines Beitrags das Ende der medientypischen Kette darstellt. Weiter wäre es unabdingbar, die «Rollen», welche die «Nutzer» (User, Teilnehmer) einerseits, der «Plattformbetreiber» andererseits haben, zu untersuchen. Das hätte möglicherweise auch noch etwas mehr Vertiefung in unsäglich komplizierte AGB und nutzerunfreundliche Optionen, in «systembedingte» Automatismen und steuerbare Abläufe vorausgesetzt, und es wäre möglicherweise auch einiges aus der Sicht des Datenschutzes zu sagen gewesen. Aber es wäre am Ende sicher nichts herausgekommen, was Facebook zu einem Medium gemacht hätte, sondern zumindest die überwiegende Anzahl der als wesentlich herausgearbeiteten Gesichtspunkte hätte dafür gesprochen, dass es sich um ein Kommunikationsmittel oder einen Kommunikationskanal, aber nicht um «Massenkommunikation» in einem herkömmlichen Sinne und damit um ein «Massenmedium» des alten Verständnisses handelt. Nur ein solches kann aber die Privilegierung von «Teilnehmern» rechtfertigen, während nicht zu sehen ist,

14 Im Wesentlichen aus den Gründen, die ich in meinem Beitrag gemäss Fn. 1 auf S. 119 f. dargelegt habe. 
warum irgendwelche beliebigen Formen der elektronischen Kommunikation («online») anders bewertet werden soll als diejenige, die «offline» erfolgt.

56 Aber eben: Davon finden wir keine Spur, sondern ein nur höchst unbefriedigendes Aneinanderreihen un- tereinander kaum verbundener Stichworte, sozusagen eine Art von «Assoziationsketten», die keine der Stellung und Bedeutung des Bundesgerichts würdige Urteilsbegründung sind. Leider aber typisch für seine Rechtsprechung, die sich Jahr um Jahr vom Niveau früherer Jahrzehnte entfernt. 